África (São Paulo, 1978, Online), São Paulo, n. 42, p. 86-108, 2021

http://dx.doi.org/

\title{
Os desafios da investigação linguística em África: o caso de moçambique
}

Resumo: $\mathrm{O}$ estudo das línguas moçambicanas tem conhecido melhores tempos nas últimas décadas como resultado do que se pode chamar crescimento da consciência dos moçambicanos sobre a necessidade de construir uma nação forte, próspera e desenvolvida, o que só é possível numa sociedade democrática onde cada ator está consciente do seu papel no processo de desenvolvimento. A decisão sobre a introdução das línguas no ensino básico em Moçambique, através do modelo de ensino bilingue, fundamentada na necessidade de remoção de um dos mais importantes obstáculos do sucesso escolar, marcou um dos momentos mais importantes de rutura entre a visão nacionista (Fishman 1968) da política linguística moçambicana adotada nos primeiros tempos da independência e a visão nacionalista (Fishman op. cit.) e democrática onde a contribuição de cada moçambicano na construção de estado de direito é valorizada. Este triunfo de visão nacionalista sobre a visão nacionista coloca aos moçambicanos, sobretudo aos linguistas, para começar, grandes desafios. Com efeito, ao mesmo tempo que a referida decisão veio estimular a investigação tanto através de estudos visando analisar o impacto da decisão política de introdução das línguas no ensino (Moisés 2011, Ngun-

Apresentado no Seminário Internacional sobre A Pesquisa na Universidade Africana no Contexto da Globalização: Perspetivas Epistemológicas Emergentes, Novos Horizontes Temáticos, Desafios. Painel: Novas formas de pesquisa linguística na África atual em termos teóricos e metodológicos e dificuldades de ensinar línguas africanas em universidades. CEA-USP, S. Paulo, 3 a 5 de Setembro de 2012.

2 Centro de Estudos Africanos. Universidade Eduardo Mondlane, Maputo, Moçambique 
ga et al. 2010) na educação em geral como da descrição da gramática das línguas visando municiar os professores, alunos e técnicos de educação de conhecimentos sobre a estrutura e o funcionamento destas línguas (NGUNGA 2002, NGUNGA e SIMBINE 2012, LANGA 2012, MACALANE 2012). A presente comunicação apresenta o estado atual da investigação das línguas africanas em Moçambique à luz dos desenvolvimentos mais recentes da situação sociopolítica do país.

Palavras-chave: línguas moçambicanas; educação bilingue; nacionismo; nacionalismo.

INTRODUÇÃO

O continente africano conheceu os momentos mais terríveis da história da humanidade com a colonização europeia que resultou da sua partilha na conferência de Berlin (novembro de 1884-fevereiro de 1895). Na altura em que se concluiu o processo de partilha da África, milhares de estados tradicionais africanos tinham sido "amalgamados em pouco mais de quarenta colônias europeias e protetorados na África” (MEREDITH, 2005, p.2). Apesar de a consciência da colonização e a necessidade de lutar pela libertação terem surgido mais cedo a mercê dos maus tratos que os colonialistas europeus infligiam aos povos africanos, a confiança na possibilidade de os países africanos se tornarem independentes viria a surgir apenas com o fim da II Guerra Mundial. Com efeito, os africanos tinham tomado parte na II Guerra Mundial em defesa dos países que os colonizavam. Lutando ao lado dos seus colegas brancos, os atiradores senegaleses (era assim que eram chamados os soldados africanos no exército francês e, por extensão, todos os soldados africanos envolvidos na guerra na Europa) descobriram que eles não eram europeus e que os europeus eram estrangeiros na África. Descobriram também que os europeus eram seres humanos com sentimentos, capazes de chorar para aliviar a dor, com contradições entre si e, mais do que tudo isso, que eram tão mortais como qualquer ser humano. Por isso e mais, quando regressaram a África, começaram a criar movimentos reivindicativos pró-independência que obrigariam as potências europeias a introduzirem reformas na sua forma de governação dos territórios africanos. 
ARMINDO NGUNGA Os desafios da investigação linguística em áfrica: o caso de moçambique

Foi assim que a França, por exemplo, organizou um referendo que culminaria com a criação de federações regionais dos territórios africanos de língua francesa. Os portugueses introduziram algumas reformas cosméticas promovendo as colônias a "províncias ultramarinas", primeiro, e "estados", mais tarde. Estas reformas, não convenceram aos africanos a abdicarem da necessidade de lutar pela independência dos seus países.

Os britânicos optaram por avançar gradualmente para concessão de autonomia dos seus territórios, o que culminaria com as independências. Por isso é que as antigas colônias britânicas conseguiram as suas independências sem recurso à luta armada. Alguns países colonizados pela França, conseguiram também as suas independências sem recurso às armas, depois da vitória da Argélia de Ben Bella sobre a França em 1962. Na sua maioria, as independências africanas tiveram lugar na década de sessenta, com a exceção dos países de língua oficial portuguesa cuja potência colonial teimava em lutar até ao último homem para perpetuar o sofrimento dos povos que se batiam para a sua libertação que só viria a ter lugar na década seguinte. Por isso, a década de 1960 é chamada a década das independências africanas.

Como se sabe, a altura da independência é sempre momento de grandes euforias, apesar dos múltiplos problemas de que as pessoas só se apercebem no dia que se segue ao do desfraldar da bandeira. Entre esses vários problemas que aos países se colocavam desde os básicos tais como os de acesso à educação, à saúde, até os mais complexos relacionados com a construção e desenvolvimento de infraestruturas de comunicações para pôr os países na senda do progresso socioeconômico e de estabilidade, colocava-se um como denominador comum aos diferentes países, o das línguas.

As línguas africanas eram vistas, por um lado, como um importante símbolo de cultura e nacionalismo africanos. Por isso, deviam ser valorizadas e desenvolvidas. Por outro lado, por causa da sua diversidade em muitos países, eram vistas como nocivas ao processo de criação de uma nação unida, forte e próspera. Por isso tinham de ser eliminadas para não exacerbar os ânimos tribais porque os territórios africanos são, geralmente, multiétnicos e multiculturais. Além disso, o seu papel na construção da nação com uma administração moderna era nula por causa de se encontrarem em estágio incipiente do seu desenvolvimento, sem sistema de escrita nem descrição, o que se traduzia na sua incapacidade de comunicar conceitos modernos e científicos. 
Essas diferentes formas de olhar para as línguas africanas foram traduzidas por Fishman (1968) como dois tipos de política linguística dos países em desenvolvimento. Por um lado, a política virada para o "nacionismo" (nationism) adotando apenas uma única língua oficial, a do antigo colonizador, ignorando todas as línguas africanas. Esses países advogavam que pretendiam construir nações fortes e unidas o que na sua perspetiva, só se podia conseguir através de uma língua com tradição escrita e de utilização na administração moderna e na ciência. Alguns exemplos deste grupo de países são: Costa do Marfim, Mali, Burkina Faso, Angola, Moçambique, entre outros. Por outro lado, havia o grupo de países que adotavam uma política linguística virada para o "nacionalismo" (nationalism) escolhendo uma língua africana, de comunicação mais ampla, para funcionar como língua nacional na educação, na administração, na política, na economia e em todas as esferas da vida social, ao lado da língua oficial europeia, ignorando todas as outras línguas africanas. Deste grupo de países podem citar-se os exemplos de Tanzânia, Malawi, Quénia, entre outros, como os mais representativos. Um terceiro grupo de países, muito pequeno, que se pode considerar subgrupo do segundo em termos de filosofia nacionalista, mas mais progressista que aquele, adotou uma outra postura mais próxima da realidade africana. Estes países adotaram mais do que uma língua africana além da língua da antiga potência colonial. Deste grupo fazem parte a Zâmbia, o Zimbabwe e mais tarde veio juntar-se a África do Sul que apareceu como um dos países mais progressistas do mundo do ponto de vista de política linguística ao apresentar onze línguas oficiais.

A presente comunicação visa partilhar alguns aspetos da pesquisa linguística em Moçambique e seu impacto no redesenho da política linguística do país à luz do desenvolvimento da situação sociopolítica e dos desafios da globalização. Para o efeito, ela aborda: 1. A situação linguística de Moçambique; 2. O lugar das línguas nas diferentes etapas da história de Moçambique; 3. A pesquisa linguística em Moçambique e seu impacto na política linguística; 4. Os desafios da pesquisa linguística em termos metodológicos e epistemológicos e as dificuldades de ensino das línguas africanas. 5. Conclusões. 
ARMINDO NGUNGA Os desafios da investigação linguística em áfrica: o caso de moçambique

\section{A situação linguística de MoçAMbiQue}

Moçambique é, tal como a maioria dos países africanos, um país multilingue e multicultural onde coexistem com o Português, a língua oficial, muitas línguas moçambicanas pertencentes ao grupo bantu cujos estudos e desenvolvimento nunca foram encorajados pelo governo português. Apesar de além destas, existirem no país muitas outras línguas não africanas entre europeias e asiáticas, as línguas bantu constituem o principal substrato linguístico do país porquanto elas são as línguas maternas de mais de oitenta por cento de moçambicanos.

Os dados sobre a situação linguística de Moçambique têm-se apresentado como um problema cuja solução não se vislumbra no horizonte. Desde os dados do primeiro recenseamento geral da população realizado em 1980, a informação sobre a situação linguística de Moçambique tem variado de acordo com as várias fontes, o que impede que se possa afirmar categoricamente em termos de quantas línguas são faladas efetivamente no país. Veja-se a tabela que se segue, que é ilustrativa do carácter divergente das informações existentes sobre esta matéria:

Tabela 1: Número de Línguas Moçambicanas

\begin{tabular}{|l|c|c|}
\hline Fonte & Ano & N $^{\circ}$ de línguas \\
\hline Cabral & 1975 & 15 \\
\hline Cardoso & 2005 & 25 \\
\hline Conselho Coordenador do Recenseamento & 1983 & 16 \\
\hline Firmino & 2000 & 24 \\
\hline Katupha & 1988 & 13 \\
\hline INE & 2010 & 21 \\
\hline Liphola & 2009 & 41 \\
\hline Lopes & 1999 & 20 \\
\hline Marinis & 1981 & 8 \\
\hline Matsinhe & 2005 & 19 \\
\hline NELIMO & 1989 & 20 \\
\hline Ngunga & 1987 & 33 \\
\hline Ngunga & 1992 & 21 \\
\hline Yai & 1983 & 13 \\
\hline
\end{tabular}

Fonte: Ngunga (2011, in Multilingual Matters) 
África (São Paulo, 1978, Online), São Paulo, n. 42, p. 86-108, 2021

A estes números de línguas deve-se acrescentar sempre 1 (a língua de sinais que raramente aparece nas estatísticas de línguas moçambicanas). Portanto, ao responder a uma questão sobre o número de línguas em Moçambique, o mais seguro é dizer algo como "entre 9 e 43 línguas ou mais". Este fato é outro desafio que se coloca à linguística em Moçambique. "É urgente a realização de um recenseamento linguístico com base no qual se possa saber quantas línguas existem e quais as suas variantes, o que poderia permitir a elaboração de um atlas linguístico do país. Um tal estudo ajudaria também a esclarecer a problemática de línguas vs. variantes cuja falta de clareza parece favorecer a proliferação de línguas em Moçambique.

Para efeitos desta comunicação vamos considerar os resultados finais oficiais do recenseamento geral da população realizado em 2007 e divulgados em 2010 pelo Instituto Nacional de Estatística de Moçambique. Esses dados indicam que são faladas em Moçambique 22 línguas (incluindo o grupo de a língua de sinais) por cerca de 16.000 .000 de pessoas de cinco ou mais anos de idade distribuídas por províncias de acordo com a tabela que se segue:

Tabela 2: Línguas faladas pela população de 5 ou mais anos de idade.

\begin{tabular}{|c|l|c|c|l|}
\hline $\mathbf{N}^{\circ}$ & Línguas & Falantes & $\mathbf{\%}$ & Províncias onde são faladas \\
\hline 1 & Makhuwa & 4.105 .122 & 25.92 & $\begin{array}{l}\text { Cabo Delgado, Nampula, Niassa, } \\
\text { Zambézia, Sofala }\end{array}$ \\
\hline 2 & Portuguese & 1.828 .239 & 11.54 & Todas as províncias \\
\hline 3 & Changana & 1.682 .438 & 10.62 & $\begin{array}{l}\text { Gaza, Maputo, Maputo City, } \\
\text { Inhambane, Niassa }\end{array}$ \\
\hline 4 & Sena & 1.314 .190 & 8.30 & Manica, Sofala, Tete, Zambézia \\
\hline 5 & Lomwe & 1.202 .256 & 7.59 & Nampula, Niassa, Zambézia \\
\hline 6 & Chuwabu & 989.579 & 6.24 & Sofala, Zambézia \\
\hline 7 & Nyanja & 905.062 & 5.71 & Niassa, Tete, Zambézia \\
\hline 8 & Ndau & 702.455 & 4.43 & Manica, Sofala \\
\hline 9 & Tshwa & 469.343 & 2.96 & Gaza, Inhambane, Maputo, Sofala \\
\hline 10 & Nyungwe & 457.290 & 2.88 & Manica, Tete \\
\hline 11 & Yaawo & 340.204 & 2.14 & Cabo Delgado, Niassa \\
\hline 12 & Makonde & 268.450 & 1.69 & Cabo Delgado \\
\hline 13 & Tewe & 255.704 & 1.61 & Manica \\
\hline 14 & Rhonga & 239.333 & 1.52 & $\begin{array}{l}\text { Gaza, Maputo, Cidade de Maputo, } \\
\text { Inhambane }\end{array}$ \\
\hline
\end{tabular}


ARMINDO NGUNGA Os desafios da investigação linguística em áfrica: o caso de moçambique

\begin{tabular}{|c|l|c|c|l|}
\hline 15 & Tonga & 203.924 & 1.28 & $\begin{array}{l}\text { Gaza, Inhambane, Maputo, Cidade de } \\
\text { Maputo }\end{array}$ \\
\hline 16 & Copi & 169.811 & 1.07 & $\begin{array}{l}\text { Gaza, Inhambane, Maputo, Cidade de } \\
\text { Maputo }\end{array}$ \\
\hline 17 & Manyika & 133.190 & 0.84 & Manica \\
\hline 18 & Cibalke & 102.778 & 0.64 & Manica \\
\hline 19 & Mwani & 77.915 & 0.49 & Cabo Delgado \\
\hline 20 & Koti & 60.780 & 0.38 & Nampula \\
\hline 21 & Swahili & 15.250 & 0.10 & Cabo Delgado \\
\hline & $\begin{array}{l}\text { Outras } \\
\text { LM }\end{array}$ & 310.259 & 1.95 & Todas as províncias \\
\hline & $\begin{array}{l}\text { Lgs dos } \\
\text { Sinais }\end{array}$ & 7.059 & 0.05 & Todas as províncias \\
\hline & Total & $15.833 .572^{4}$ & 100 & Todas as províncias \\
\hline
\end{tabular}

Fonte: INE (2010).

As 22 línguas registadas pelo INE (2010) testemunham o caráter plural do país onde coexistem diversas línguas, culturas e povos com formas peculiares de perceção e interpretação do mundo. A tabela que se segue apresenta a distribuição pelas províncias do país de falantes de português como língua materna em Moçambique:

Tabela 3: Falantes de Português das dez províncias e da Cidade de Maputo.

\begin{tabular}{|c|l|c|c|c|}
\hline \multicolumn{2}{|l|}{ Província } & População total & Falantes de Português & \% \\
\hline 1 & Cidade de Maputo & 959.474 & 412.162 & 43.0 \\
\hline 2 & Maputo Province & 1.025 .871 & 283.665 & 27.7 \\
\hline 3 & Sofala & 1.338 .709 & 177.655 & 13.3 \\
\hline 4 & Zambézia & 3.021 .246 & 277.906 & 9.2 \\
\hline 5 & Nampula & 3.183 .399 & 277.223 & 8.7 \\
\hline 6 & Niassa & 904.784 & 61.223 & 6.8 \\
\hline 7 & Manica & 1.131 .269 & 64.057 & 5.7 \\
\hline 8 & Inhambane & 1.058 .135 & 57.782 & 5.4 \\
\hline 9 & Gaza & 1.024 .911 & 49.231 & 4.8 \\
\hline
\end{tabular}

No original dos dados do Censo são chamadas "línguas dos mudos". Geralmente desinga-se no plural por que ainda não estão sistematizadas nem padronizadas.

4 Moçambique tem atualmente (2012) cerca de 23.000.000 habitantes. 
África (São Paulo, 1978, Online), São Paulo, n. 42, p. 86-108, 2021

\begin{tabular}{|l|l|l|l|l|}
\hline 10 & Cabo Delgado & 1.306 .724 & 44.914 & 3.4 \\
\hline 11 & Tete & 1.415 .977 & 44.988 & 3.3 \\
\hline
\end{tabular}

Fonte: Ngunga e Bavo (2011).

Os números apresentados na tabela acima demonstram que a política assimilacionista colonial falhou em matéria de transformar a língua portuguesa em língua de toda a população moçambicana, o que já se tinha visto mesmo na altura da independência em que menos de $5 \%$ da população moçambicana falava a língua portuguesa. É preciso sublinhar que a maioria dos moçambicanos que atualmente fala português como segunda língua aprendeu esta língua depois da independência. Quanto a transformá-la em língua materna, o processo está muto mais lento do que se poderia esperar apesar do aumento de número de casamentos entre pessoas de diferentes grupos étnicos, sobretudo entre a geração que anda à volta dos cinquenta anos de idade ou mais nova, que se espera se comunique em português que depois é língua materna dos seus descendentes.

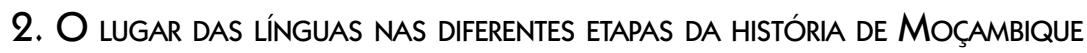

Esta secção vai, de forma breve, periodizar o percurso da política linguística de Moçambique para facilitar a compreensão do que se vive hoje e os desafios da pesquisa linguística no país.

\subsection{Período pré-COlONIAL (PRÉ-1895)5}

Há muito pouco a dizer sobre o período pré-colonial no que diz respeito a situação linguística de Moçambique uma vez que as fronteiras atuais do país, que definem a sua configuração atual, são o resultado da colonização, isto é, da conferência de Berlim já referida que definiu claramente os contornos das suas fronteiras. Antes dessa altura, havia, no espaço hoje ocupado por Moçambique, como em toda a África, uma série de estados-nações que

\footnotetext{
5 Apesar de a presença portuguesa em Moçambique ser muito anterior a esta data (ca. de quatro séculos antes), esta data é tomada como referência para aquilo que se considera ocupação efetiva por Portugal do território que hoje se chama Moçambique.
} 
ARMINDO NGUNGA Os desafios da investigação linguística em áfrica: o caso de moçambique

se supõe que fossem monolingues e cada um desfrutando a vida à sua maneira, umas vezes atacando o estado vizinho para dilatar o tamanho dos seus domínios, outras vezes perdendo as suas terras a favor do outro vizinho, até ao momento em que alguns descobriram formas de romper com este ciclo vicioso lançando-se ao comércio de longa distância com povos de outras latitudes. Para isso, foram instrumentais os principais cursos de água (Zambeze, o Limpopo, o Lago Niassa, entre outros) que se constituíram em principais rotas naturais de desenvolvimento de relações entre as populações ribeirinhas, e o conhecimento da geografia que permitiu abrir caminhos nas matas em direção ao mar. Nesta situação, o conhecimento da língua materna bastava para sobreviver dentro das fronteiras nacionais. No caso de Moçambique, não há registo de uma língua franca que tenha intermediado a comunicação entres povos falantes de línguas diferentes como aconteceu noutras partes da África.

\subsection{Período COLONIAL (1895-1975)}

Uma avaliação preliminar dos estudos portugueses sobre Moçambique permite concluir que os estudos linguísticos nunca foram a grande prioridade do conhecimento sobre este país e seus povos. Sabe-se que durante muitos anos houve missões de investigação (sobre a antropologia, geografia, a hidrografia, a orografia, a agricultura, a fauna, a flora, os recurso minerais, os grupos étnicos e a sua organização social, a filosofia e as formas de pensamento dos africanos, etc.) constituídas por especialistas e professores universitários de renome. Do nosso conhecimento, essas missões nunca incluíram linguistas. Os estudos linguísticos, muito poucos, que se conhecem são de autoria de pessoas individuais, quer como funcionários da administração (VIANA, 1961) que matavam a solidão escrevendo "qualquer coisa" sobre a língua dos africanos sob sua governação, ou membros de grupos filantrópicos ou religiosos (BENOIT, 1907; KAMTEDZA, 1964; MOREIRA, 1924; PRATA, 1960; RIBEIRO, 1965; SANTOS, 1941; TORREND, 1900; ZENI s/d.) sem a devida preparação especializada que se requeria dos estudiosos de outras áreas de conhecimento.

Esta postura é aquela que condizia com a política colonial em geral e a política linguística em particular, que faziam acreditar que os africanos, 
África (São Paulo, 1978, Online), São Paulo, n. 42, p. 86-108, 2021

que eram meio portugueses, um dia seriam portugueses plenos com a morte de todas as suas línguas e, consequentemente, quando a língua portuguesa fosse o seu único meio de comunicação. E foi de acordo com esta visão que em 1917 foi aprovado o estatuto do assimilado através da Portaria $\mathrm{n}^{\circ}$ 137/1917, de 10 de Janeiro, publicada no Boletim Oficial da Província de Moçambique, $\mathrm{n}^{\circ} 2$, I Série. Daí que, durante o período colonial, nunca tenha havido cursos superiores de linguística de uma forma geral e de linguística africana em particular, nas universidades africanas que, aliás, são uma criação recente (1962). Os grupos de religiosos que, por causa da sua vocação, ensinavam ou escreviam as línguas africanas, faziam-no também contra os supremos interesses do estado colonial. Portanto, devido a essa política assimilacionista vigente na altura, as línguas africanas, apesar de seu número e sua diversidade, não constituíam área de conhecimento digna de estudos científicos para os portugueses.

Nessa altura, a população residente em Moçambique era constituída por brancos, mestiços, negros assimilados e negros indígenas. A língua portuguesa era, obviamente, a língua oficial e único meio de educação formal, aquela em se comunicavam os brancos, mestiços e assimilados. Os assimilados eram pressionados a abandonar, entre outros aspetos das culturas africanas, as línguas dos seus antepassados para adotarem a língua portuguesa que passava a ser sua e que também deviam ensinar aos seus descendentes.

Foi ao longo do período colonial em que foi crescente o desprezo das línguas africanas, apelidadas de dialetos e línguas que nunca podiam ser faladas por portugueses (negros) assimilados. Nas escolas, haviam castigos severos para aqueles que por distração ou necessidade ousassem pronunciar uma palavra numa língua africana, um esforço claro de desencorajamento do seu uso e tentativa da sua supressão.

Os indígenas eram os que compunham a maioria da população moçambicana, pobre, analfabeta que só se comunicava nas línguas africanas. Portanto, as populações negras não assimiladas ou estavam fora do sistema da educação ou tinham de lutar para vencer a barreira linguística levando uma média de 3 a 4 anos na primeira classe (primeira série), se não desistissem.

A consequência imediata desta política assimilacionista foi que somente os filhos dos colonos e dos poucos assimilados (profissionais tais como enfermeiros, professor primários, motoristas, alguns funcionários subalternos 
ARMINDO NGUNGA Os desafios da investigação linguística em áfrica: o caso de moçambique

da administração, carpinteiros e poucos mais) podiam beneficiar da política linguística colonial na educação. Embora um número razoável de moçambicanos tivesse conseguido desistir das suas culturas e línguas, milhões de moçambicanos não conseguiram frequentar a escola ou frequentaram por poucos dias ou meses e depois desistiram por causa da hostilidade e violência que caracterizavam o ambiente linguístico escolar.

\subsection{Período da lUta ARMAda (1964-1975)}

Cansados de opressão e humilhação coloniais, e goradas as tentativas visando o convencer o governo português a conceder a independência por meios pacíficos, os moçambicanos liderados pela FRELIMO desencadearam a luta armada de libertação nacional a 25 de Setembro de 1964.

Como se pode imaginar, embora a esmagadora maioria dos combatentes da FRELIMO fosse constituída de camponeses analfabetos, a liderança era constituida de pessoas escolarizadas, aquelas que ou tinha estudado nas escolas missões, ou nas escolas oficiais por causa do seu estatuto de assimilados ou de filhos de assimilados. Por isso, não é de estranhar que apesar de ser língua de minoria, português tenha sido escolhido como, língua oficial da FRELIMO, língua de relações exteriores, com epíteto de língua da unidade nacional, por se considerar língua supraétnica ou 'etnicamente neutra'. Foi com esta decisão que passou a ser proibido o uso das línguas africanas nas escolas da FRELIMO. Todavia, as línguas africanas continuaram o seu papel de meio imprescindível e insubstituível da comunicação entre os guerrilheiros nas matas de Moçambique. Além das suas línguas maternas, os guerrilheiros tinham o Swahili, uma das línguas oficiais da Tanzânia, país que foi a retaguarda da FRELIMO, como uma língua de comunicação mais ampla, uma língua supra-étnica e de verdadeira unidadde nacional. Era o Swahili a língua com que os guerrilheiros se comunicavam com as populações das zonas libertadas ou semi-libertadas no interior das províncias de Cabo Degaldo e Niassa onde, esta língua foi o verdadeiro símbolo da libertação de Moçambique. Alias, nos primeiros anos da independência era assim que se identificava o combatente da FRELIMO, e mesmo hoje continua a ser a língua dos veteranos da luta de libertação. 
África (São Paulo, 1978, Online), São Paulo, n. 42, p. 86-108, 2021

Contra o discurso oficial que as caracterizava como línguas de discriminação étnica e regional, numa altura em que o combate ao tribalismo tinha a mesma importância que o combate ao colonialismo, as línguas moçambicanas continuaram a florescer na boca do povo através das canções revolucionárias criativamente inventadas pelos guerrilheiros na frente da batalha expressando a invencibilidade das forças populares e da cultura moçambicana, expressando a moçambicanidade, a unidade nacional, a africanidade e o internacionalismo.

\subsection{PeRíodo Pós INDEPENDÊNCIA, DURANTE O MONOPARTIDARISMO (1975-90)}

Com a independência do país celebrada a 25 de Junho de 1975, o país adotou um regime monopartidário, como resultado da aplicação dos acordos de Lusaka que puseram fim aos dez anos de luta armada de libertação nacional. Nos referidos acordos, o governo português reconhecia a FRELIMO, o movimento de libertação que derrotara o colonialismo português, como único e legítimo representante do Povo moçambicano. Assim, a FRELIMO governou o país durante quinze anos como partido único adotando uma política linguística monolítica, fundamentada no nacionismo de Fishman (1968) que em nada refletia a complexa realidade multilingue e multicultural do país. Com efeito, como continuação da tradição desenvolvida durante a luta armada, a língua portuguesa seria reconhecida pela constituição da jovem nação como a única língua oficial, isto é, a única língua que se devia usar na administração a todos os níveis de governação, na justiça, na educação, na saúde, no parlamento, em todas as atividades formais da vida dos moçambicanos. $\mathrm{O}$ paradoxal nisto é que Moçambique acabava de herdar uma pesada herança colonial de $95 \%$ de analfabetismo, num país em que a língua portuguesa só se podia aprender na escola. Para minimizar o défice comunicacional, o governo organizou campanhas de alfabetização e educação de adultos que visava ensinar a língua portuguesa a todos os operários e camponeses, sobretudo os organizados em aldeias e cooperativas de produção.

A elevação do Português ao estatuto de única língua oficial, implicou a proibição do uso das línguas moçambicanas em espaços públicos em nome da unidade nacional expressa no slogan "é preciso matar a tribo para que nasça a nação" (FRELIMO), como também retirou do convívio dos combatentes 
ARMINDO NGUNGA Os desafios da investigação linguística em áfrica: o caso de moçambique

o Swahili cuja função fora considerada terminada na noite da declaração da independência nacional. Massificou-se a educação, mas, tal como tinha acontecido no período colonial, havia pesados castigos reservados para as crianças que por engano ou necessidade de comunicação pronunciassem uma palavra de uma língua moçambicana. Esta postura traz à superfície a ideologia de assimilado que se libertou do colonialismo, mas não conseguiu libertar-se de um dos instrumentos mais representativos da dominação colonial, a língua.

\subsection{Período de democracia multipartidária (pós-1990)}

A democratização do país iniciou com as profundas mudanças políticas preconizadas pela Constituição da República de 1990 que introduziu o multipartidarismo, liberdades de imprensa e de expressão e o sistema de eleições periódicas regulares de cinco em cinco anos (gerais, presidenciais, provinciais e autárquicas). Com estas reformas os resultados das pesquisas linguísticas ganharam maior alento e visibilidade contribuindo para o crescimento da consciência dos moçambicanos sobre a necessidade de construção de uma nação forte, próspera e desenvolvida, o que só é possível numa sociedade democrática onde cada ator está consciente do seu papel no processo de desenvolvimento.

Um dos marcos importantes do processo de democratização do país e expressão da vontade política de criação de condições para que todos os moçambicanos tenham capacidade de participar foi a introdução das línguas maternas da maioria dos moçambicanos na educação formal. Estudos do Instituto Nacional do Desenvolvimento da Educação já (INDE 1990, 1996) há muito que tinham demonstrado que uma das razões fundamentais por que o desperdício escolar era elevado tinha a ver com o fato de as crianças serem obrigadas a estudar em língua que não conheciam, e que os professores, produtos desse mesmo sistema, conheciam muito mal.

A filosofia subjacente ao processo de introdução de uma política linguística inclusiva do ensino através das línguas maternas é aquela que é defendida por muitos estudiosos entre os quais Fishman (2006) para quem as línguas minoritárias devem ser consideradas como recursos naturais de uma nação, imprescendíveis para seu enriquecimento tanto linguístico quanto cultural e como diferencial para seus cidadãos diante da globalização e da mo- 
África (São Paulo, 1978, Online), São Paulo, n. 42, p. 86-108, 2021

dernização. Para que esses recursos se consolidem e se desenvolvam, é preciso implementar políticas de planeamento que estejam centradas na democracia cultural e nos direitos iguais dos grupos étnicos. Foi caminho que o governo de Moçambique finalmente escolheu.

Por outro lado, se a democratização do país significa tomada de poder pelo povo, ela deve associar-se ao desenvolvimento de autonomia das pessoas como processo contínuo de tomada de atitudes transformadoras do aprender levadas pela curiosidade do mundo e pela reflexão crítica do próprio agir sobre o mundo (Cummins (2000). Só um ser humano que aprende na sua própria língua desde tenra idade é capaz de participar nos processos democráticos e compreender a necessidade de participar em consciência nos deveres cívicos e de cidadania. Por isso, tratando-se de um país multilingue e multiétnico que experimentou dezesseis anos de guerra fratricida, não sobrava muitas opções de política linguística da educação do país senão aquela que fosse a mais abrangente e inclusiva possível em que todos os moçambicanos se sentissem reconhecidos e com que todos os moçambicanos se identificassem. Foi por isso aprovado que o ensino bilingue iniciasse em dezesseis línguas e em escolas experimentais distribuídas por todas as províncias do país. A justificação é que todas as crianças moçambicanas são iguais perante a constituição.

\section{A PESQUISA LINGUÍSTICA EM MOÇAMBIQUE E SEU IMPACTO NA POLÍTICA LINGUíSTICA}

Como se disse acima, a pesquisa das línguas moçambicanas era quase inexistente no período colonial em Moçambique. Por isso, além de poucos materiais escritos por missionários nada ou pouco mais, nada existia de substancial sobre a descrição e análise das línguas moçambicanas na altura da independência em 1975. Como resultado deste estado de coisas, não havia linguistas bantuístas capacitados para realizar investigação ou emitir opinião informada sobre questões linguísticas em geral. Por outras palavras, não havia bases para se realizar uma pesquisa linguística no país, uma situação que deve ter contribuído sobremaneira para dar corpo aos argumentos a favor da visão nacionista e da não introdução das línguas moçambicanas nas escolas, forma suprema de promoção e valorização dos moçambicanos, seus conhecimentos, sua cultura e sua autoestima que são fatores-chave do desenvolvimento. 
ARMINDO NGUNGA Os desafios da investigação linguística em áfrica: o caso de moçambique

Em 1980, o então Departamento de Letras Modernas da Faculdade de Letras da Universidade Eduardo, criou o NELIMO. ${ }^{\circ}$ Desde então, esta unidade trabalhou na investigação, promoção e desenvolvimento das línguas moçambicanas até 2007, altura em que deixou de existir e as suas atividades de pesquisa das línguas moçambicanas passaram praticamente para o Centro de Estudos Africanos. Durante os 27 anos da sua existência, o NELIMO realizou atividades tais como workshops, debates e seminários sobre línguas moçambicanas e ações de formação. Entre as ações realizadas, destacam-se como as mais importantes a realização do I Seminário sobre a Padronização da Ortografia de 15 Línguas Moçambicanas (Agosto de 1988), cujo relatório foi publicado no ano seguinte (NELIMO 1989) e, dez anos mais tarde, do II Seminário cujo relatório foi publicado um ano depois (SITOE e NGUNGA, 2000). Como continuação do trabalho do NELIMO, em 2008, o Centro de Estudos Africanos liderou o processo de realização do III Seminário que tinha por objetivo, entre outros assuntos, retomar alguma parte das discussões iniciadas em 1988. Os resultados deste seminário foram também publicados em relatórios (NGUNGA e FAQUIR (2011).

O papel do NELIMO ao longo dos 27 anos da sua existência foi instrumental na elevação da consciência linguística dos moçambicanos tendo até sido determinante para o início das reflexões sobre a política linguística do país que hoje estão a ter lugar à luz do desenvolvimento da situação sociopolítica e dos desafios da globalização.

Por isso, a extinção do NELIMO em 2007 não deveria significar a paralisação das atividades de pesquisa das línguas moçambicanas. Daí que de 2007 a esta parte, o Centro de Estudos Africanos da Universidade Eduardo Mondlane tenha pegado o estandarte e tenha sido a face mais visível da pesquisa linguística em Moçambique, publicando os resultados das suas pesquisas sobre descrição das línguas moçambicanas e de elaboração de dicionários monolingues, duas áreas que constituem a maior prioridade da agenda da área linguística. As gramáticas descritivas facultam o conhecimento sempre necessário para quem precise de aprofundar os segredos de funcionamento de uma língua, incluindo os professores alunos e outros pesquisadores. Os dicionários monolingues fazem parte do processo de empoderamento e liber-

6 Núcleo de Estudo de Línguas Moçambicanas. 
África (São Paulo, 1978, Online), São Paulo, n. 42, p. 86-108, 2021

tação das línguas. A nossa perceção é de que as línguas africanas têm de se desenvolver para poderem ser veículo de desenvolvimento de que todos falam. Por isso, é preciso desenvolver tanto o conhecimento profundo sobre elas como a capacidade de elas exprimirem conceitos complexos da sociedade moderna, sem se esquecer do conhecimento universal que é resultado da conquista milenar da humanidade. É de salientar que os materiais aqui produzidos através da Coleção "As nossas línguas" têm tido boa receptividade.

A decisão sobre a introdução de línguas moçambicanas no ensino básico tomada em 2002 e implementada a partir de 2003, através do modelo de ensino bilingue, constitui o sinal evidente de uma política linguística justa, inclusiva e revolucionária mesmo no contexto das políticas linguísticas da África e do mundo. Essa decisão fundamentada na necessidade de remoção de um dos mais importantes obstáculos do sucesso escolar, marcou um dos momentos mais importantes de rutura entre a visão nacionista (FISHMAN, 1968) da política linguística moçambicana adotada nos primeiros tempos da independência e a visão nacionalista (Fishman op. cit.) e democrática onde a contribuição de cada moçambicano na construção de estado de direito é devidamente valorizada. Este triunfo de visão nacionalista sobre a visão nacionista trouxe aos moçambicanos, sobretudo aos linguistas, para começar, grandes desafios. Desafio de realizar estudos integrados ou não em programas de pós-graduação sobre a educação bilingue (NHONGO, 2009; MOISÉS, 2010; NGUNGA et al., 2010; PATEL, 2006, 2012), desafio de iniciar processo de descrição das línguas (LANGA, 2008, 2012, MACALANE, 2012; NGUNGA, 2002; NGUNGA e SIMBINE, 2012) e desafio de elaboração de dicionários nestas línguas (NGUNGA e MARTINS, 2012; SITOE, 1996, 2012; SITOE et al., 2008). Tendo desde cedo ficado claro que o sucesso da academia nesses desafios só podia ser possível com a inclusão da componente formação, a Faculdade de Letras e Ciências Sociais da Universidade Eduardo Mondlane abriu, em 2006, o mestrado e doutorado para formar quadros com competência científica para realizar a pesquisa da qualidade que o país exige. Até agora já se graduaram quatro doutorados nas áreas de linguística aplicada e de linguística teórica e descritiva e 28 mestres nestas áreas e na área de linguística comportamental. Enquanto isso, o Centro de Estudos Africanos tem-se empenhado na pesquisa na área das línguas moçambicanas que tem 
ARMINDO NGUNGA Os desafios da investigação linguística em áfrica: o caso de moçambique

municiado os implementadores da educação bilingue em material de consulta especializado difícil de se encontrar no país.

Embora se reconheça os esforços desenvolvidos e que resulta nestes números, não se deve perder de vista também que estes ainda não satisfazem as necessidades do país. Basta lembrar que a descrição da maioria das pouco mais de vinte línguas ainda é incipiente ou mesmo inexistente. A introdução das línguas no ensino implica produção de dezenas de títulos nestas línguas, o que significa formar não só bons falantes das línguas, mas, sobretudo escritores e escreventes nestas línguas além de pesquisadores e outros estudiosos das línguas em questão.

\section{OS DESAFIOS DA PESQUISA LINGUíSTICA EM TERMOS METODOLÓGICOS E EPISTEMOLÓGICOS E AS DIFICULDADES DE ENSINO DAS LÍNGUAS AFRICANAS}

$\mathrm{Na}$ era da globalização, nenhum povo de país da periferia se deve dar ao luxo de se distrair em matérias de línguas e cultura sem se arriscar a dormir no seu país e acordar no estrangeiro porque dominado culturalmente. Por isso, seria importante que as universidades africanas introduzissem o ensino das línguas africanas como disciplinas transversais e obrigatórias. No caso de Moçambique, as línguas africanas a ensinar nas universidades deveriam ser aquelas das zonas onde as universidades se localizam. Esta seria também uma contribuição importante da academia no resgate da moçambicanidade e da africanidade na era da globalização.

A pesquisa linguística tem aqui mais um desafio a enfrentar. Tendo sido sugerido no parágrafo anterior que língua ensinar, o que é um passo importante, resta saber como ensinar. É uma questão metodológica importante que muitas vezes compromete o sucesso de ensino das línguas africanas. A título de sugestão, as línguas locais seriam ensinadas como língua materna, aos que já as falam, com ênfase na escrita, na gramática e em alguns aspetos da modernização linguística. Neste sentido, as aulas teriam de ser interativas para se aproveitar no máximo todo o potencial que os estudantes universitários de várias áreas de saber podem dar como contribuição para o desenvolvimento e modernização da língua.

Aos não falantes das línguas locais, seriam ensinados os rudimentos de língua desde o nível elementar ao avançado passando pelo médio durante 4 
África (São Paulo, 1978, Online), São Paulo, n. 42, p. 86-108, 2021

semestres, como se faz com a aprendizagem de qualquer língua estrangeira. A ideia seria de permitir que o graduado pudesse ter um comando da língua para ser capaz de trabalhar, sem barreiras linguísticas, com as populações do local onde tivesse estudado. As matérias seriam, assim, organizadas de tal maneira que no final o graduado fosse fluente na oralidade e na escrita daquela que em princípio seria a sua língua de trabalho com as comunidades a quem iria servir.

É claro que são algumas ideias que poderiam ser melhoradas na forma da sua concretização, uma vez que se trata que Moçambique é um país onde as mentes de muitas pessoas estão formatadas a pensar que o acesso à universidade é uma oportunidade para se libertarem da tradição e do atraso que este tipo de tradição "implica".

De qualquer maneira, este conhecimento de várias línguas por moçambicanos falantes de outras línguas iria, em grande medida, cimentar a unidade nacional, a conquista mais preciosa da revolução de 25 de Setembro. ${ }^{7}$

\section{CONCLUSÕES}

Como ficou visto, o estudo das línguas africanas é muito importante não só pelo seu contributo no desenvolvimento da teoria linguística (Hyman, 2003) como também porque as línguas são o depositário das filosofias que sintetizam o saber milenar que permitiu que as comunidades que as usam resistissem e sobrevivessem a todo o tipo de investidas inimigas ao longo da história. Por isso, a sua pesquisa pode abrir portas para a modernização desse conhecimento e permitir o redesenho dos caminhos do desenvolvimento africano contribuindo, desta forma, para o desenvolvimento da humanidade.

Nessa direção, um passo importante já foi dado em Moçambique através da introdução das línguas moçambicanas no sistema de ensino, um gesto de significado histórico e cultural incomensurável para o país e para o mundo uma vez que tal valoriza não só as línguas moçambicanas e as pessoas que as falam, como valoriza sobretudo o ser humano porque a aquisição dos conhecimentos escolares através da língua que a pessoa fala é um direito de todo o

7 Refere-se a "Dia da Revolução", data do início da luta armada de libertação nacional de Moçambique. 
ARMINDO NGUNGA Os desafios da investigação linguística em áfrica: o caso de moçambique

ser humano. Todavia, é preciso que se reconheça que esse fato representa um grande desafio não só para os linguistas que são os profissionais em matéria de línguas, como também para todos os pesquisadores moçambicanos e africanos de todas as áreas de conhecimentos (matemáticos, físicos, astrónomos, geógrafos, historiadores, cientistas políticos, informáticos, educacionistas, biólogos, etc.) a quem cabe a tarefa de produzir nas suas línguas os materiais de ensino das disciplinas das suas áreas, o que logicamente, não cabe aos linguistas.

Esta reflexão demonstra que a academia moçambicana precisa desesperadamente de apoio e cooperação de outras academias do mundo, sobretudo das universidades brasileiras, tanto na formação de quadros qualificados para responderem aos desafios que a pesquisa linguística nas mais variadas dimensões coloca, como na pesquisa das línguas no presente. Tanto num caso como noutro, esta colaboração só dará os frutos almejados se se desenhar um programa que defina claramente as tarefas comuns e de cada parte. Por exemplo, como tarefas comuns poder-se-ia mencionar a coorientação dos estudantes (moçambicanos e brasileiros) do mestrado e ou do doutorado e a participação de projetos de pesquisa conjunta. Além disso, outro ponto a considerar seria visitas de quatro/cinco semanas de pesquisadores moçambicanos ao Brasil e brasileiros a Moçambique, para concluir a redação de um livro ou outro de um projeto de pesquisa em momentos em que a disponibilidade de tempo, a serenidade e mesmo a distância em relação à casa são imprescindíveis. Aqui se coloca a questão fundamental. Onde encontrar os recursos? Esta é a grande questão que precisamos de discutir e responder. Responder a esta pergunta seria um dos primeiros temas da discussão sobre a cooperação pois, tal como em outras áreas de conhecimento, também em Linguística é muito importante a colaboração dos especialistas dos vários países, das várias universidades, das várias experiências tanto no ensino como na pesquisa. Por isso, os professores e pesquisadores moçambicanos e brasileiros precisam de se dar as mãos em defesa desta nobre causa.

\section{REFERÊNCIAS}

Benoit, W. 1907. Grammatica portugueza em lingua ronga. Missão Suissa em Lourenço Marques. Lausanne: Imprimerie Georges Bridel, \& $C^{a}$. 
África (São Paulo, 1978, Online), São Paulo, n. 42, p. 86-108, 2021

Benson, C. 1997. Relatório Final sobre o Ensino Bilingue: Resultados da Avaliação Externa da Experiência de Escolarização Bilingue em Moçambique. Maputo, Moçambique: INDE.

Cabral, A. 1975. Empréstimos Linguísticos nas línguas Moçambicanas. Empresa Moderna. Lourenço Marques.

Cardoso, P. 2005. Atlas da Lusofonia - Moçambique. Lisboa: Instituto Português da Conjuntura Estratégica e Editora Prefácio.

Conselho Coordenador do Recenseamento. 1983. $1^{\circ}$ Recenseamento Geral da População: Informação Pública. Maputo, Moçambique.

Cummins, J. (2000). Bilingual children's mother tongue: Why is it important for education? 2001. February. Sprogforum, 7, (19) 15-20.

Firmino, G. 2000. Situação Linguística de Moçambique. Maputo: Instituto Nacional de Estatística.

Fishman, J. A. (2006). Language Maintenance, Language Shift, and Reversing Language Shift. In Bhatia, T. K. \& Ritchiew C. (eds.). The handbook of bilingualism. Malden. Oxford: Blackwell Publishing Ltd. P. 406-436.

Fishman, J. 1968. Language policy in developing nations. New York: Wiley.

Hyman, L. 2003. Why describe African Languages? World Congress of African Linguistics

4/Annual Conference on African Languages 34. Rutgers Keynote Address.

INDE/MINED. 1996. Ensino Bilíngue: Uma Alternativa para a Escolarização Inicial (EP1) nas Zonas Rurais. PEBIMO. Maputo: INDE

Kamtedza 1964. Elementos de Gramática Cinyanja. Junta de Investigação do Ultramar. Lisboa.

Katupha 1988. O panorama linguístico de Moçambique e a contribuição da linguística na definição de uma política linguística apropriada. Lua Nova: Artes e Letras. Pp27-32. Maputo.

Langa, D. 2008. O aspecto no passado afirmativo na morfologia verbal do Changana. (Dissertação de Mestrado não publicada). Maputo: Faculdade de Letras e Ciências Sociais. Universidade Eduardo Mondlane.

Langa, D. 2012. Morfofonologia da Forma Verbal em Changana. (Tese de Doutoramento não publicada). Maputo: Faculdade de Letras e Ciências Sociais. Universidade Eduardo Mondlane.

Liphola, M. 2009. Desafios na Gestão do Património Linguístico em Moçambique. Comunicação apresentada na II Conferência Nacional sobre a Cultura. Maputo, 14-16 de Maio. 
ARMINDO NGUNGA Os desafios da investigação linguística em áfrica: o caso de moçambique

Lopes, A. J. 1999. The Language Situation in Mozambique. In R. B. Kaplan and R. B.

Baldauf, Jr., (eds.). Language Planning in Malawi, Mozambique and Philippines. Pp. 86131. III Series: Multilingual Matters (Series):113. Short Run Press, Ltd. Great Britain.

Macalane. G. 2012. A variação paramétrica das interrogativas parciais em Cinyanja. (Tese de Doutoramento não publicada). Maputo: Faculdade de Letras e Ciências Sociais. Universidade Eduardo Mondlane.

Marinis, H. 1981. Línguas Bantu: sua história sua classificação. MS. Maputo: NELIMO, UEM.

Matsinhe, S. 2005. The Language Situation in Mozambique: Current Developments and Prospects. in Birgit Brock-Utne \& Rodney K. Hopson (Eds.). Languages of Instruction for African Emancipation: Focus on Postcolonial Contexts and Considerations. The Centre for Advanced Studies of African Society (CASAS). Pp. 119-147

Meredith, M. 2005. The State of Africa: A History of Fifty Years of Independence. The Free Press. A imprint of Simon and Shuster, Uk, Ltd.

Moisés, L. 2010. Educação bilingue em Moçambique: Estratégias de leccionação na fase de transição de L1 para L2 como meio de ensino. (Dissertação de Mestrado não publicada). Maputo: Faculdade da Educação. Universidade Eduardo Mondlane. Maputo.

NELIMO, 1989. Relatório do I Seminário sobre a Padronização da Ortografia de Línguas Moçambicanas. NELIMO/INDE. Maputo.

Ngunga, A. 2011 a. Minidicionário de Ciyaawo-Português e Portguês-Ciyaawo. Maputo: Associação Progresso.

Ngunga, A. 2011 b. Monolingual education in a multilingual setting: The case of Mozambique. Journal of Multicultural Discourses. Vol 6, No. 2, July 2011, 177-196. Routledge: Tailor and Francis Group.

Ngunga, A. 2004. Introdução à Linguística Bantu. Maputo: Universidade Eduardo Mondlane. Imprensa Universitária.

Ngunga, A. 2002. Elementos de Gramática da Língua Yao. Maputo: Universidade Eduardo Mondlane. Imprensa Universitária.

Ngunga, A. 1992. Breves notas sobre a situação linguística de Moçambique. In Notícias. $28 / 2 / 92$

Ngunga, A. 1987. As línguas Bantu de Moçambique. Limani: Linguística e Literatura, 2:59-70

Ngunga, A. e P. Martins, 2012. Xihlamusarito xa Xichangana. Colecção: “As nossas Línguas" VI. Maputo: Centro de Estudos Africanos. Universidade Eduardo Mondlane.

Ngunga, A. e M. Simbine 2012. Gramática Descritiva das Língua Changana. Colecção: 
África (São Paulo, 1978, Online), São Paulo, n. 42, p. 86-108, 2021

“As nossas Línguas" V. Maputo: Centro de Estudos Africanos. Universidade Eduardo Mondlane.

Ngunga, A. e N. Bavo, 2011. Práticas Linguísticas em Moçambique: Avaliação da Vitalidade Linguística em Seis Distritos. Colecção: “As nossas Línguas” IV. Maputo: Centro de Estudos Africanos. Universidade Eduardo Mondlane.

Ngunga, A. e O. Faquir, 2011. Padronização da Ortografia de Línguas Moçambicanas: Relatório do III Seminário. Colecção: “As nossas Línguas” III. Maputo: Centro de Estudos Africanos. Universidade Eduardo Mondlane.

Ngunga, A. et al. 2010. Educação bilingue na Província de gaza: Avaliação de um modelo de ensino. Colecção: "As nossas Línguas” II. Maputo: Centro de Estudos Africanos. Universidade Eduardo Mondlane.

Nhongo, N. 2009. A habilidade escrita dos alunos no programa de educação bilingue no ensino básico em Moçambique. Tese de Mestrado. Lisboa: Faculdade de Lestras.

Patel, S. A. (2006). Olhares sobre a Educação Bilingue e seus Professores numa Região de Moçambique. (Dissertação de Mestrado não publicada). Campinas: Unicamp.

Patel, S. A. (2012).Um olhar para a formação de professores de educação bilingue em Moçambique: Foco na construção de posicionamentos a partir do lócus de enunciação e actuação. (Tese de Doutorado não publicada). Campinas: Unicamp

Prata, P. 1960. Gramática da Língua Macua (e seus dialectos). Cucujães: Sociedade Missionária Portuguesa.

Ribeiro, A. 1965. Gramática de Changana. 1ª edição. Caniçado. Moçambique: Editorial Evangelizar.

S/A. 1917. Portaria $n^{\circ}$ 137/1917, de 10 de Janeiro. Boletim Oficial da Província de Moçambique, $n^{\circ} 2$, I Série.

Santos, L. 1941. Gramática da Língua Chope. Lourenço Marques: Imprensa Nacional de Moçambique.

Sitoe, B. 2012. Dicionário Changana-português. 2a edição. Maputo: Texto editores

Sitoe, B. 1996. Dicionário Changana-Português. Maputo: Instituto Nacional do Desenvolvimento da Educação (INDE), Ministério da Educação.

Sitoe, B. N. Mahumana e P. Langa. 2008. Dicionário Ronga - Português. Maputo: CIPROMETRA.

Sitoe, B., e Ngunga, Armindo (eds.). 2000. Relatório do II Seminário sobre a Padronização da Ortografia de Línguas Moçambicanas. Maputo: Livraria Moderna.

Torrend, J. 1900. Grammar of the Language of the Lower Zambezi. Chipanga. Zambezia. 
ARMINDO NGUNGA Os desafios da investigação linguística em áfrica: o caso de moçambique

Ugembe, Z. 2011. Tom Verbal em Xitshwa. Tese de Mestrado em Linguística. (Dissertação de Mestrado não publicada). Maputo: Faculdade de Letras e Ciências Sociais. Universidade Eduardo Mondlane.

Yai, B. 1983. Elements for a policy of National Languages. UNESCO.

Zeni. L. (s.d.). Gramática da Língua Ecwabo - Quelimane. (s.l., s. ed.)

Recebido por email em 23/10/2012 